\title{
Suppression of Vertical Vibration in Railway Vehicles by Damping Force Control of Primary Suspension Using an LQG Controller*
}

\author{
Yoshiki SUGAHARA**, Tadao TAKIGAMI**, Akihito KAZATO***, \\ Reiko KOGANEI** and Mitsuji SAMPEI ${ }^{\dagger}$ \\ ** Vehicle Noise and Vibration Laboratory, Railway Technical Research Institute, \\ 2-8-38, Hikari-cho Kokubunji-shi, Tokyo, 185-8540 Japan \\ E-mail: sugahara@rtri.or.jp \\ *** Running Gear Laboratory, Railway Technical Research Institute \\ $\dagger$ Department of Mechanical and Control Engineering, Tokyo Institute of Technology, \\ 2-12-1, Oh-Okayama Meguro-ku, Tokyo, 152-8552 Japan
}

\begin{abstract}
Suppression of the vertical bending vibration of carbodies has recently become essential in improving the ride comfort of railway vehicles. In this paper, we propose a method of controlling vibration in the primary suspension of rolling stock to reduce carbody vibration. Systems conceivable for this purpose include a semi-active suspension system with variable axle dampers that can control damping force continuously by command current to the damping force control valve. Based on LQG control theory, we carried out numerical simulations and performed excitation testing with a carbody equivalent to an actual Shinkansen vehicle fitted with variable axle dampers to selectively suppress the first mode bending vibration of the carbody. The results show that this LQG control method reduces the power spectral density (PSD) of acceleration on the floor more effectively than the sky-hook control method, which does not consider the vibration modes of the carbody.
\end{abstract}

Key words : Railway Vehicle, Semi-active Suspension, Variable Damper, Vibration Control, Bending Vibration

\section{Introduction}

In recent years, vertical elastic vibration has been seen to occur on the carbodies of railway vehicles (in the form of the first mode bending vibration in particular). Since the frequency of this vibration is close to the frequency band of 4 to $8 \mathrm{~Hz}$ where human beings are sensitive to vertical vibration, the phenomenon adversely affects ride comfort, and measures to reduce vibration are required. For the first mode bending vibration of the carbody, therefore, a number of measures to prevent vibration have been discussed and tested ${ }^{(1)(2)}$. Most of these techniques are divided roughly into two categories: one is to dissipate the vibration energy by damping elements added to the carbody and the other is to directly apply a force to suppress vibration to the carbody.

In contrast, we have proposed a method to control the primary suspension as a way of suppressing the vibration of trucks (a major source of carbody excitation) and subsequently reduce carbody vibration without directly applying a damping force to suppress elastic vibration. Two systems (active and semi-active) are conceivable as methods to control the primary suspension, but we have adopted the latter in view of its robustness, cost performance and ease of ensuring safety, and are now developing technologies related to it.

In a previous report ${ }^{(3)}$, we introduced the possibility of reducing the first mode bending vibration of the carbody by applying the truck frame sky-hook control law. As a method to 
reduce carbody vibration focusing on the first mode bending vibration, however, a control law based on a vehicle model is also considered applicable. We therefore applied the LQG control law based on a low-dimension vehicle model, and compared its vibration-reducing effect with that obtained using the truck frame sky-hook control law. This paper reports the results of excitation tests carried out on a vehicle equivalent to an actual Shinkansen car at the rolling stock test plant of the Railway Technical Research Institute (RTRI).

\section{System composition}

\subsection{An outline of the overall system composition}

Figure 1 shows the composition of the vehicle model tested. Its primary suspension is composed of axle springs (coil springs) and axle dampers (hydraulic dampers), and the secondary suspension system consists of air springs.

The vibration of a vehicle with such primary and secondary suspension systems is detected using acceleration sensors installed on the carbody and the truck. Based on data from the detected vibration, the optimal damping force to be generated by the each variable axle damper (referred to below as the variable axle damper) is calculated by a controller, and is used to suppress the vibration of the vehicle.

\subsection{Variable axle damper ${ }^{(3)}$}

Figure 2 shows the prototype variable axle damper. In this figure, the damper is shown laterally, but in reality it is fixed in the vertical direction between the axle box and the truck frame (see Fig. 1). It has an installation length of $370 \mathrm{~mm}$ and a maximum damping force of about $6 \mathrm{kN}$, which are approximately the same as the values of a conventional passive axle damper.

This variable axle damper uses a reversing-type electromagnetic proportional relief valve (4) in the damping control mechanism. Figure 3 shows the characteristics of the command current versus the damping force when the piston speed is constant. As the damping force and direction can be switched using the command current, it is possible to compose a variable mechanism with only a small number of damping control valves.

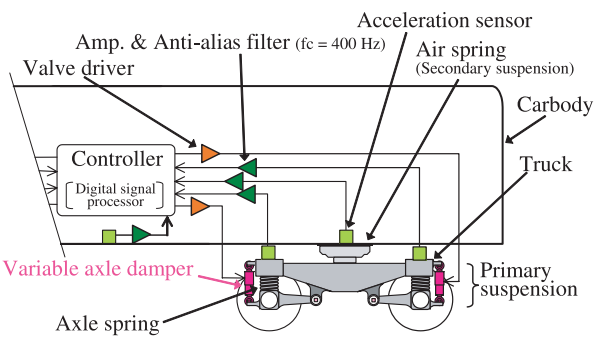

Fig. 1 Primary suspension damping control system for railway vehicle

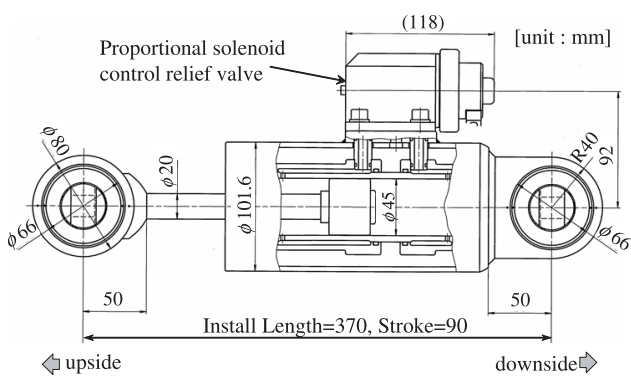

Fig. 2 Drawing of variable axle damper 


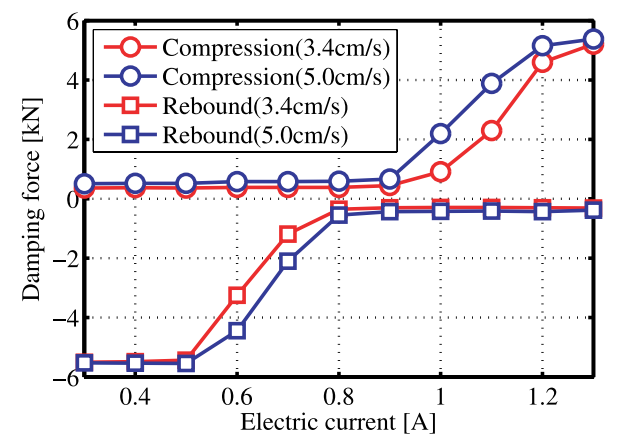

Fig. 3 Charasteristics of variable axle damper

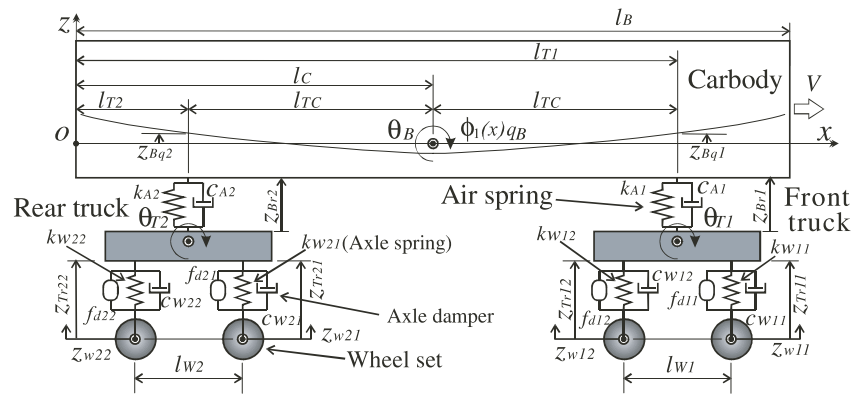

Fig. 4 7-DOF railway vehicle model

\section{Models of vehicle and variable axle damper}

\subsection{Derivation of a vehicle model with seven degrees of freedom}

Figure 4 shows the vehicle model used to design the controller and perform simulations. All other values of displacement, except that of the vertical displacement of the axle box $z_{W i j}$, are expressed in relative terms. These are displacement of axle spring $z_{T r i j}$, air spring $z_{B r i}$ and first bending mode $q_{B}$, where the suffixes represent $i=1$ (front truck), $i=2$ (rear truck), $j=1$ (front axle) and $j=2$ (rear axle).

We assume that the carbody, having mass $m_{B}$ and pitching inertia moment $J_{B}$, is a uniform elastic beam with free ends, bending rigidity $E I$ and internal viscous damping $\mu I$, and is supported at two points by air springs, whose vertical stifffness and damping coefficient are denoted by $k_{A i}$ and $c_{A i}$ respectively. In discussing the carbody vibration mode, we address only the vertical translational movement, pitching and first bending mode, which significantly affect the carbody ride comfort. The following equations of motion for the carbody are then obtained $^{(5)}$ :

$$
\begin{aligned}
\frac{m_{B}}{4}\left\{\sum_{i=1}^{2} \sum_{j=1}^{2}\left(\ddot{z}_{W i j}+\ddot{z}_{T r i j}\right)+\sum_{i=1}^{2} 2 \ddot{z}_{B r i}\right\} & \\
= & -\sum_{i=1}^{2}\left\{k_{A i}\left(z_{B r i}+\phi_{1}\left(l_{T i}\right) q_{B}\right)+c_{A i}\left(\dot{z}_{B r i}+\phi_{1}\left(l_{T i}\right) \dot{q}_{B}\right)\right\} \\
\frac{J_{B}}{4 l_{T C}}\{ & \left.-\left(\sum_{j=1}^{2}\left(\ddot{z}_{W 1 j}+\ddot{z}_{T r 1 j}\right)+2 \ddot{z}_{B r 1}\right)+\left(\sum_{j=1}^{2}\left(\ddot{z}_{W 2 j}+\ddot{z}_{T r 2 j}\right)+2 \ddot{z}_{B r 2}\right)\right\} \\
= & l_{T C}\left\{\left(k_{A 1}\left(z_{B r 1}+\phi_{1}\left(l_{T 1}\right) q_{B}\right)+c_{A 1}\left(\dot{z}_{B r 1}+\phi_{1}\left(l_{T 1}\right) \dot{q}_{B}\right)\right)\right. \\
& \left.-\left(k_{A 2}\left(z_{B r 2}+\phi_{1}\left(l_{T 2}\right) q_{B}\right)+c_{A 2}\left(\dot{z}_{B r 2}+\phi_{1}\left(l_{T 2}\right) \dot{q}_{B}\right)\right)\right\} \\
m_{B}\left(\ddot{q}_{B}+\right. & \left.2 \zeta_{1} \omega_{1} \dot{q}_{B}+\omega_{1}^{2} q_{B}\right) \\
= & -\sum_{i=1}^{2} \phi_{1}\left(l_{T i}\right)\left\{-k_{A i}\left(z_{B r i}+\phi_{1}\left(l_{T i}\right) q_{B}\right)-c_{A i}\left(\dot{z}_{B r i}+\phi_{1}\left(l_{T i}\right) \dot{q}_{B}\right)\right\}
\end{aligned}
$$


In the above equations, $i=1,2$ and $j=1,2$, while $\phi_{1}(x)$ is the eigenfunction of the carbody first bending mode. Denoting by $\lambda_{1}(=4.730)$ the solution for the frequency equation $\cos \lambda \cosh \lambda=1$ of the first bending mode, we obtain the following $\omega_{1}$ and $\zeta_{1}$ :

$$
\omega_{1}=\left(\frac{\lambda_{1}}{l_{B}}\right)^{2} \sqrt{\frac{E I l_{B}}{m_{B}}}, \quad \zeta_{1}=\frac{\mu I}{2 E I} \omega_{1}
$$

The truck frame is dealt with as a rigid body with mass $m_{T i}$ and pitching inertia moment $J_{T i}$. The primary suspension supporting the truck frame is composed of axle springs and dampers, and is represented by a dynamic model with virtual actuators installed in parallel. It is characterized by a spring constant $k_{W i j}$, a damping coefficient $c_{W i j}$ and a damping force $f_{d i j}$ generated by each variable axle damper. On the assumption that the axle boxes move only in the vertical direction and the truck frames move in the vertical translation and pitching modes, the equations of motion for the truck frame are given for $i=1$ and 2 as:

$$
\begin{aligned}
& \frac{1}{2} m_{T i}\left(\ddot{z}_{W i 1}+\ddot{z}_{T r i 1}+\ddot{z}_{W i 2}+\ddot{z}_{T r i 2}\right) \\
&=-k_{W i 1} z_{T r i 1}-k_{W i 2} z_{T r i 2}+k_{A i}\left(z_{B r i}+\phi_{1}\left(l_{T i}\right) q_{B}\right) \\
&-c_{W i 1} \dot{z}_{T r i 1}-c_{W i 2} \dot{z}_{T r i 2}+c_{A i}\left(\dot{z}_{B r i}+\phi_{1}\left(l_{T i}\right) \dot{q}_{B}\right)+f_{d i 1}+f_{d i 2} \\
& \frac{J_{T i}}{l_{W i}}\left(-\ddot{z}_{W i 1}-\ddot{z}_{T r i 1}+\ddot{z}_{W i 2}+\ddot{z}_{T r i 2}\right) \\
&=-\frac{l_{W i}}{2}\left(-k_{W i 1} z_{T r i 1}+k_{W i 2} z_{T r i 2}-c_{W i 1} \dot{z}_{T r i 1}+c_{W i 2} \dot{z}_{T r i 2}+f_{d i 1}-f_{d i 2}\right)
\end{aligned}
$$

As a result, we can express the equations of motion for the carbody and truck frame as:

$$
\begin{aligned}
& \boldsymbol{M}_{v} \ddot{z}+\boldsymbol{C}_{v} \dot{z}+\boldsymbol{K}_{v} z=\boldsymbol{W}_{v} \boldsymbol{w}+\boldsymbol{D}_{v} \boldsymbol{f}
\end{aligned}
$$

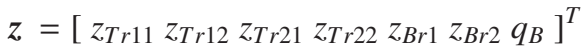

$$
\begin{aligned}
& \boldsymbol{w}=\left[\begin{array}{llll}
\ddot{z}_{W 11} & \ddot{z}_{W 12} & \ddot{z}_{W 21} & \ddot{z}_{W 22}
\end{array}\right]^{T} \\
& \boldsymbol{f}=\left[\begin{array}{llll}
f_{d 11} & f_{d 12} & f_{d 21} & f_{d 22}
\end{array}\right]^{T}
\end{aligned}
$$

Here, $\boldsymbol{M}_{v}, \boldsymbol{C}_{v}, \boldsymbol{K}_{v}, \boldsymbol{W}_{v}, \boldsymbol{D}_{v}$ are real constant matrices.

As the observation quantities $\boldsymbol{y}$, we adopt the vertical vibration acceleration at three points on the carbody floor (at the carbody center and directly above the two trucks) and at the point right above each axle box on the truck frame. The following state equations are then obtained from Eq.(7):

$$
\begin{aligned}
& \dot{\boldsymbol{x}}=\boldsymbol{A} \boldsymbol{x}+\boldsymbol{B} \boldsymbol{f}+\boldsymbol{G} \boldsymbol{w} \\
& \boldsymbol{y}=\boldsymbol{C} \boldsymbol{x}+\boldsymbol{D} \boldsymbol{f} \\
& \boldsymbol{x}=\left[\begin{array}{l}
\left.\boldsymbol{z}^{T} \dot{z}^{T}\right]^{T} \\
\boldsymbol{y} \frac{1}{2} \sum_{j}\left(\ddot{z}_{W 1 j}+\ddot{z}_{T r 1 j}\right)+\ddot{z}_{B r 1}+\phi_{1}\left(l_{T 1}\right) \ddot{q}_{B} \\
\frac{1}{2} \sum_{j}\left(\ddot{z}_{W 2 j}+\ddot{z}_{T r 2 j}\right)+\ddot{z}_{B r 2}+\phi_{1}\left(l_{T 2}\right) \ddot{q}_{B} \\
\frac{1}{4} \sum_{i} \sum_{j}\left(\ddot{z}_{W i j}+\ddot{z}_{T r i j}\right)+\frac{1}{2} \sum_{i} \ddot{z}_{B r i}+\phi_{1}\left(l_{C}\right) \ddot{q}_{B} \\
\ddot{z}_{W 11}+\ddot{z}_{T r 11} \\
\ddot{z}_{W 12}+\ddot{z}_{T r 12} \\
\ddot{z}_{W 21}+\ddot{z}_{T r 21} \\
\ddot{z}_{W 22}+\ddot{z}_{T r 22}
\end{array}\right]
\end{aligned}
$$

Here, $\boldsymbol{A}, \boldsymbol{B}, \boldsymbol{C}, \boldsymbol{D}, \boldsymbol{G}$ are real constant matrices. 


\subsection{Model of variable axle damper for simulations ${ }^{(3)}$}

The model of the mechanism to generate and control the damping force, which is incorporated in the variable axle damper, can be regarded as a system with a circuit consisting of an orifice and a proportional solenoid control relief valve installed in parallel between the damper piston and an accumulator (see Fig.5).

In other words, it is assumed that the damping force builds up at speed $\alpha_{d}$ times the square of the damper piston speed $v_{d i j}$ (with $i$ and $j$ representing the damper position), and is ideally relieved by the proportional solenoid control relief valve whose relieving characteristic inclination is represented by $\beta_{d}$. This means that the damping force of the damper can be changed by adjusting the relief pressure of the proportional solenoid control relief valve when the piston speed is sufficiently high. The damper cannot generate the commanded damping force, however, if the damper piston speed and the damping force command value are in the same direction when the Karnopp approximation ${ }^{(6)}$ is applied.

To reflect the electrical and mechanical delays of the proportional solenoid control relief valve, we assume a first-order time lag characteristic with a time constant $T_{c d}[\mathrm{~s}]$ in the response $u_{d i j}$ of the valve against the damping force command value $u_{d r i j}$. Then, referring to Fig.5, we can express the relationship between the generated damping force $f_{d i j}$ and the damping force command value $u_{d r i j}$ to the damper as:

$$
\begin{aligned}
& f_{d i j}=\left\{\begin{aligned}
&-\operatorname{sign}\left(v_{d i j}\right) \cdot \min \left(\alpha_{d} v_{d i j}^{2},\right.\left.\left.u_{d i j}+\beta_{d} v_{d i j}\right)\right) \\
&\left(u_{d i j} \cdot v_{d i j}<0\right) \\
&-\operatorname{sign}\left(v_{d i j}\right) \cdot \min \left(\alpha_{d} v_{d i j}^{2},\right.\left.\left.\beta_{d} v_{d i j}\right)\right) \\
&\left(u_{d i j} \cdot v_{d i j} \geq 0\right)
\end{aligned}\right. \\
& \dot{u}_{d i j}=-u_{d i j} / T_{c d}+u_{d r i j} / T_{c d}
\end{aligned}
$$

\section{Controller design}

\subsection{LQG controller}

We now design a controller based on the vehicle model with seven degrees of freedom derived in the previous section. The damping force $f_{d i j}$ (a component of $f$ in Eq.(8)) generated by the variable axle damper is dependent on the damper stroke speed and its sign in actuality as shown in Eq.(10). In designing the controller, however, it is regarded as an actuator with a first-order lag characteristic with a time constant of $T_{c d}$ against the force command value $u_{d r i j}$ ( i.e. $u_{d i j}=f_{d i j}$ in Eq.(11) ). The following state equations are then obtained from Eq.(8), Eq.(9) and Eq.(11):

$$
\begin{aligned}
& \dot{\boldsymbol{x}}_{c}=\boldsymbol{A}_{c} \boldsymbol{x}_{c}+\boldsymbol{B}_{c} \boldsymbol{u}+\boldsymbol{G}_{c} \boldsymbol{w} \\
& \boldsymbol{y}=\boldsymbol{C}_{c} \boldsymbol{x}_{c} \\
& \boldsymbol{x}_{c}=\left[z^{T} \dot{z}^{T} \boldsymbol{f}^{T}\right]^{T} \\
& \boldsymbol{u}=\left[\begin{array}{llll}
u_{d r 11} & u_{d r 12} & u_{d r 21} & u_{d r 22}
\end{array}\right]^{T}
\end{aligned}
$$

Here, $\boldsymbol{A}_{c}, \boldsymbol{B}_{c}, \boldsymbol{C}_{c}, \boldsymbol{G}_{c}$ are real constant matrixes.

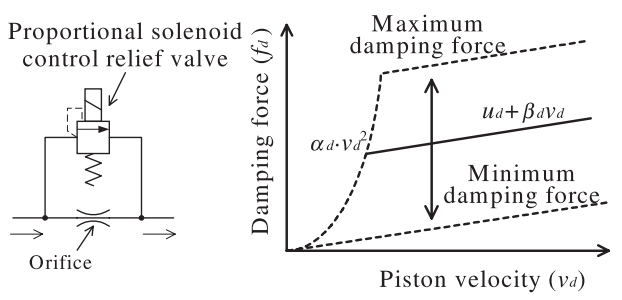

Fig. 5 Model of force control of variable axle damper

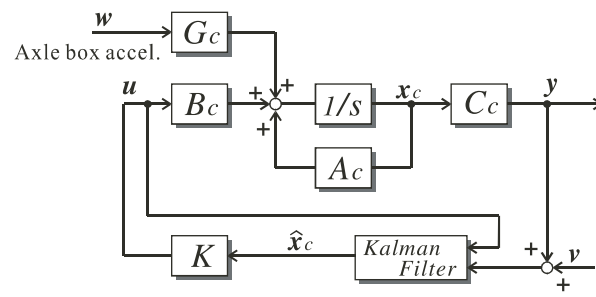

Fig. 6 Block diaglam of LQG controller 
The disturbance $\boldsymbol{w}$ for this model is the vertical vibration acceleration of the axle boxes on axles 1 to $4\left(\left[\ddot{z}_{W 11}, \ddot{z}_{W 12}, \ddot{z}_{W 21}, \ddot{z}_{W 22}\right]^{T}\right)$, which is regarded as white noise in controlling vibration by applying the LQG control law. Figure 6 shows a block diagram of the system. A Kalman filter is used to calculate the estimated state value $\hat{\boldsymbol{x}}$ from the command value $\boldsymbol{u}$ for the actuators and the observation quantities $\boldsymbol{y}$, whose components are the vertical vibration acceleration of each truck frame and that of the three points on the carbody. We use the linear quadratic regulator (LQR) with output weighting as a regulator. Since the output $y$ in observation equation (13) represents the acceleration of the truck frames and that at the three points on the carbody, however, weights cannot be set separately in the carbody and truck frame vibration modes. In place of $\boldsymbol{y}$, therefore, we use observation equation (14), whose elements are vertical translational acceleration of the carbody $\ddot{z}_{B}$, vertical acceleration of the pitching component of the carbody just above the truck $l_{T C} \ddot{\theta}_{B}$, vertical acceleration of the component of the first bending mode at the carbody center $\phi_{1}\left(l_{C}\right) \ddot{q}_{B}$, vertical translational acceleration of the truck frame $\ddot{z}_{T i}$, and vertical acceleration of the pitching component of the truck frame directly above the axle box $l_{W i} \ddot{\theta}_{T i} / 2(i=1,2)$.

$$
\boldsymbol{y}_{m}=\left[\ddot{z}_{B}, l_{T C} \ddot{\theta}_{B}, \phi_{1}\left(l_{C}\right) \ddot{q}_{B}, \ddot{z}_{T 1}, \ddot{z}_{T 2}, l_{W 1} \ddot{\theta}_{T 1} / 2, l_{W 2} \ddot{\theta}_{T 2} / 2\right]^{T}=\boldsymbol{C}_{m} \boldsymbol{x}
$$

For a system expressed by Eq.(8), the matrix $\boldsymbol{K}$ is then calculated to give state feedback value $\boldsymbol{K} \boldsymbol{x}$ to minimize the quadratic cost function (15).

$$
J=\lim _{t_{f} \rightarrow \infty} \frac{1}{t_{f}} E\left(\int_{0}^{t_{f}}\left(\boldsymbol{y}_{m}^{T} \boldsymbol{Q} \boldsymbol{y}_{m}+\boldsymbol{u}^{T} \boldsymbol{R} \boldsymbol{u}\right) d t\right)
$$

This gives the following command value $\boldsymbol{u}$ for the LQG controller:

$$
\boldsymbol{u}=-\boldsymbol{K} \hat{\boldsymbol{x}}
$$

The weighting matrix $\boldsymbol{Q}$ in Eq.(15) was set to give a large weighting value against the first bending mode, which significantly influences ride comfort.

\subsection{Truck frame sky-hook controller}

We performed truck frame sky-hook control in the vertical translational and pitching modes of the truck frame. To control the vibration of the truck frame, we applied the skyhook control to the vertical translational and pitching modes of the truck frame. For this purpose, we integrated the truck frame vertical translational vibration acceleration $\ddot{z}_{T i}$ and pitching vibration acceleration $\ddot{\theta}_{T i}(i=1,2)$ to calculate the truck frame vertical velocity $\dot{z}_{T i}$ and pitching velocity $\dot{\theta}_{T i}$ through a filter. When the sky-hook gains are denoted against the vertical translational and pitching modes using $c_{s z}$ and $c_{s \theta}$ respectively, the sky-hook force $u_{d r i j}$ required to control the vibration of the truck frame is given as:

$$
u_{d r i j}= \begin{cases}\left(-c_{s z} \dot{z}_{T i}+c_{s \theta} \dot{\theta}_{T i} l_{W i} / 2\right) / 2 & (i=1,2, j=1) \\ \left(-c_{s z} \dot{z}_{T i}-c_{s \theta} \dot{\theta}_{T i} l_{W i} / 2\right) / 2 & (i=1,2, j=2)\end{cases}
$$

This value was used as the command value for the variable axle damper.

\section{Verification by simulation}

We implemented a damping simulation on a model of vehicle equivalent to a Shinkansen car used for testing at a rolling stock test plant with the parameters listed in Table 1. Other than the mass, most of values were the same as those identified in the excitation test. The carbody had a natural frequency of $8.5 \mathrm{~Hz}$ in the first bending mode.

The models of the vehicle and the variable axle damper were assumed to follow the continuous linear model shown in $\$ 3.1$ and the continuous non-linear model shown in $\$ 3.2$ respectively. We used the controller outlined in $\$ 4$, which was discretized and had a control period of $5 \mathrm{~ms}$. As the parameters for the vehicle model used to design the LQG controller, we used the values found when the variable axle damper had the smallest damping force. We then 
Table 1 Specification parameters of vehicle for controller design

\begin{tabular}{c|l|c|l} 
parameter & value & parameter & value \\
\hline$m_{T 1}$ & $2,610 \mathrm{~kg}$ & $J_{T 1}$ & $1.33 \times 10^{2} \mathrm{~kg} \cdot \mathrm{m}^{2}$ \\
$m_{T 2}$ & $2,939 \mathrm{~kg}$ & $J_{T 2}$ & $1.28 \times 10^{2} \mathrm{~kg} \cdot \mathrm{m}^{2}$ \\
$m_{B}$ & $27,000 \mathrm{~kg}$ & $J_{B}$ & $1.21 \times 10^{6} \mathrm{~kg} \cdot \mathrm{m}^{2}$ \\
$k_{W 1 j}$ & $4.62 \times 10^{6} \mathrm{~N} / \mathrm{m}$ & $c_{W 1 j}$ & $3.69 \times 10^{4} \mathrm{~N} /(\mathrm{m} / \mathrm{s})$ \\
$k_{W 2 j}$ & $2.69 \times 10^{6} \mathrm{~N} / \mathrm{m}$ & $c_{W 2 j}$ & $2.20 \times 10^{4} \mathrm{~N} /(\mathrm{m} / \mathrm{s})$ \\
$l_{B}$ & $24.5 \mathrm{~m}$ & $k_{A i 1}$ & $1.07 \times 10^{6} \mathrm{~N} / \mathrm{m}$ \\
$l_{W i}$ & $2.50 \mathrm{~m}$ & $k_{A i 2}$ & $6.14 \times 10^{5} \mathrm{~N} / \mathrm{m}$ \\
$l_{T C}$ & $8.75 \mathrm{~m}$ & $\zeta_{1}$ & $3.6 \times 10^{-2}$ \\
$\omega_{1}$ & $54.7 \mathrm{rad} / \mathrm{s}$ & $c_{A i}$ & $3.59 \times 10^{4} \mathrm{~N} /(\mathrm{m} / \mathrm{s})$
\end{tabular}

performed sky-hook control to make the damping force the lowest when the force command value $u_{d r i j}$ was zero.

As the excitation disturbance $\boldsymbol{w}$ (see Eq.(8)), we used the axle box vertical vibration acceleration measured in a Shinkansen vehicle running test, and input it at a phase difference equivalent to that found in $300 \mathrm{~km} / \mathrm{h}$ operation. However, in consideration of the comparison with the result of the excitation test at the rolling stock test plant (referred to later), we multiplied the amplitude measured in actual running by 0.6 to make it lower than the value of the excitation amplitude limit at the rolling stock test plant. The data length of the excitation wave was about $110 \mathrm{~s}$ (equivalent to a running distance of $9.2 \mathrm{~km}$ ).

We set the variable axle damper characteristics in Eq.(10) as: $\alpha_{d i j}=3.14 \times 10^{8} \mathrm{~N} /(\mathrm{m} / \mathrm{s})^{2}$ , $\beta_{d i j}=1.48 \times 10^{4} \mathrm{~N} /(\mathrm{m} / \mathrm{s})$, and the maximum damping force was $1.18 \times 10^{4} \mathrm{~N}$. This is a practical setting, as the maximum damping force in this case is equivalent to the damping force per axle when the piston speed of a normal passive axle damper is $0.15 \mathrm{~m} / \mathrm{s}$. We set the sky-hook gain as $c_{s z}=1.0 \times 10^{5} \mathrm{~N} /(\mathrm{m} / \mathrm{s})$ and $c_{s \theta}=2.0 \times 10^{4} \mathrm{~N} /(\mathrm{m} / \mathrm{s})$. The response delay was $T_{c d}=25 \mathrm{~ms}$. The values of $\boldsymbol{Q}$ and $\boldsymbol{R}$ were as follows:

$$
\begin{aligned}
& \boldsymbol{Q}=\operatorname{diag}\left(1.0,1.31 \times 10^{-2}, 6.77 \times 10^{4}, 10,10,64,64\right) \\
& \boldsymbol{R}=\operatorname{diag}\left(1.0 \times 10^{-4}, 1.0 \times 10^{-4}, 1.0 \times 10^{-4}, 1.0 \times 10^{-4}\right)
\end{aligned}
$$

Figure 7 shows the calculated values for the power spectral density (PSD) of the truck frame and the carbody when the above disturbance was added as the vertical axle box acceleration $\boldsymbol{w}$. As a condition of FFT calculation, we used a 1/2-overlapped hanning window with a frame length of $10 \mathrm{~s}$.

Note the truck frame vertical acceleration PSD (Fig.7(a)) first. When the truck frame sky-hook control is implemented (indicated by the green line), overall vibration decreases at 5 to $12 \mathrm{~Hz}$ from the level when conventional passive axle dampers are used (shown by the gray line). As a result, the peak at $8 \mathrm{~Hz}$ in the vertical vibration acceleration PSD at the carbody center (Fig.7(b)) decreases to about $30 \%$ together with the overall vibration in the frequency band in its vicinity. This trend is the same as that of the carbody immediately above the truck (Fig.7(c)).

The orange line in Fig.7 shows the result when the first mode bending vibration of the carbody is selectively decreased using LQG control. The truck frame vibration acceleration PSD (Fig.7(a)) is selectively decreased at around $8.5 \mathrm{~Hz}$, which is the natural frequency in the carbody first bending mode. As a result, the peak at $8.5 \mathrm{~Hz}$ in the vertical vibration acceleration PSD at the carbody center (Fig.7(b)) also decreases to $15 \%$ or lower.

Finally, we compared the ride quality level $\left(L_{T}\right)$, which is a typical index used to evaluate the ride comfort of rolling stock ${ }^{(7)}$. It is said that the lower the $L_{T}$ value, the better the ride comfort, and that passengers can feel a difference in ride comfort if the $L_{T}$ value changes by more than 3 to $5 \mathrm{~dB}^{(8)}$. The legend in Fig.7 shows the calculated $L_{T}$ values. Any control law improves the $L_{T}$ value by about 3 to $5 \mathrm{~dB}$ at the carbody center compared to the level obtained when the conventional passive axle dampers are used. 


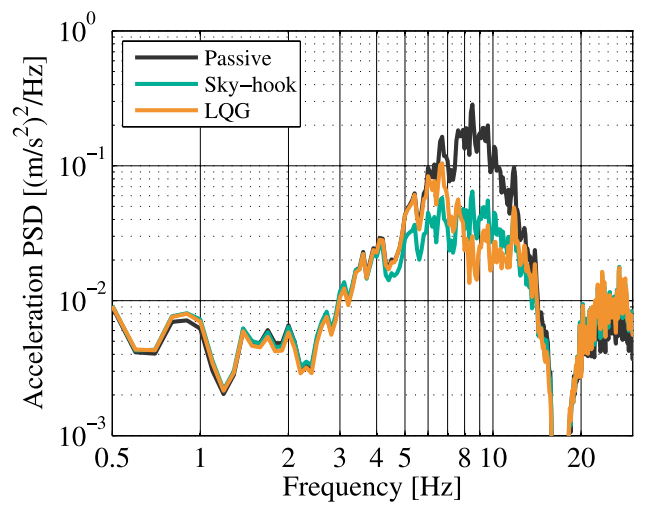

(a) Acceleration PSD of the rear truck frame

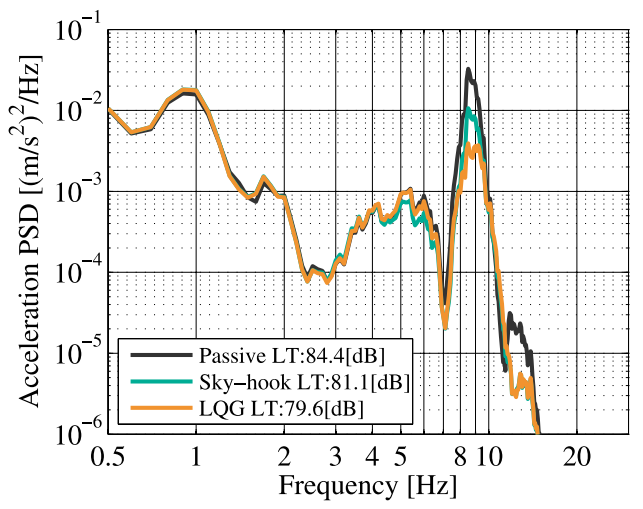

(b) Acceleration PSD at the center of the carbody floor

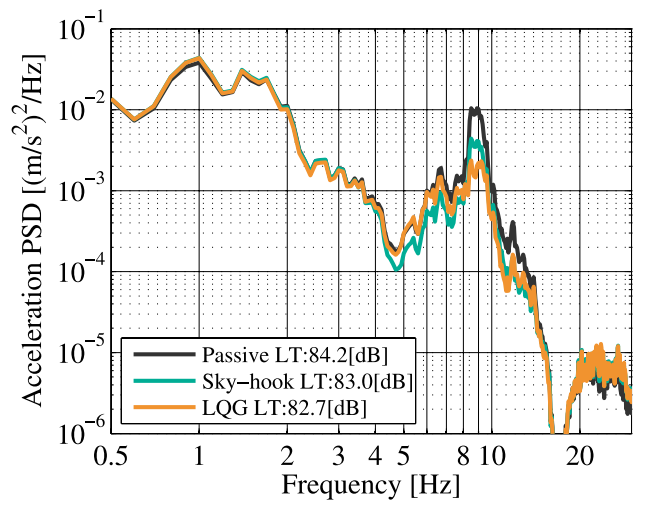

(c) Acceleration PSD at the carbody floor above the rear truck

Fig. 7 Simulated acceleration PSD with/without controlling the force of axle dampers

\section{Verification by excitation tests at a rolling stock test plant}

\subsection{Test conditions}

Excitation tests on a vehicle model equivalent to an actual Shinkansen vehicle installed with prototype variable axle dampers were implemented at the RTRI rolling stock test plant (Figs.8 and 9). The vehicle dimensions are almost the same as those in $\$ 5$. When a conventional passive axle damper is installed, $c_{W 1 j}=8.2 \times 10^{4} \mathrm{~N} /(\mathrm{m} / \mathrm{s})$ and $c_{W 2 j}=2.75 \times 10^{4}$ $\mathrm{N} /(\mathrm{m} / \mathrm{s})$.

The excitation disturbance $\boldsymbol{w}$ in the simulation of actual running (see Eq.(8)) was almost the same as that in $\S 5$. We excited the vehicle at a phase difference equivalent to that found in $300 \mathrm{~km} / \mathrm{h}$ operation, except that the amplitude in actual running was multiplied by 0.6 to 


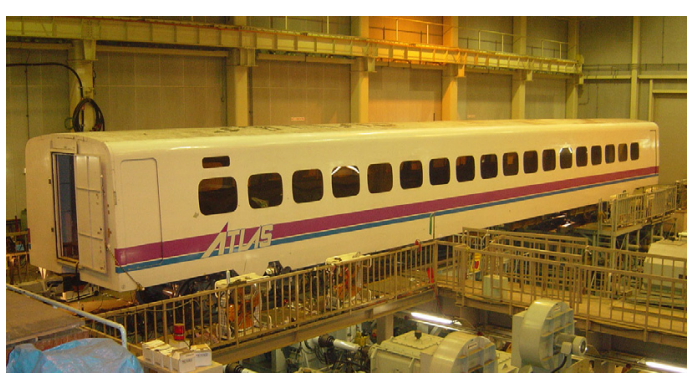

Fig. 8 Rolling stock test plant

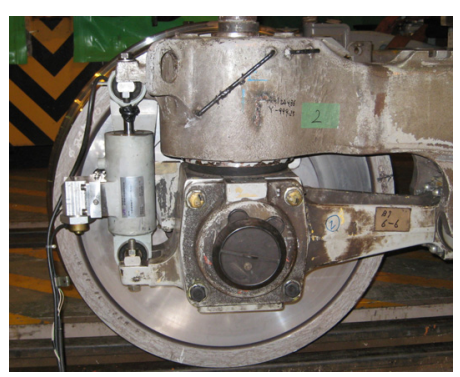

Fig. 9 Installation of variable axle damper

enable observation of the limited value of excitation amplitude at the rolling stock test plant.

The LQG controller was designed as a continuous system and discretized for installation. The control frequency was $1 \mathrm{kHz}$. Weight $\boldsymbol{Q}$ (one of the controller's design parameters) in Eq.(15) was set to give a large weighting value against the first mode bending vibration acceleration of the carbody as:

$$
\begin{aligned}
& \boldsymbol{Q}=\operatorname{diag}\left(0,0,2.03 \times 10^{6}, 1.0 \times 10^{2}, 1.0 \times 10^{2}, 6.4 \times 10^{3}, 6.4 \times 10^{3}\right) \\
& \boldsymbol{R}=\operatorname{diag}\left(1.0 \times 10^{-4}, 1.0 \times 10^{-4}, 1.0 \times 10^{-4}, 1.0 \times 10^{-4}\right)
\end{aligned}
$$

\subsection{Test results}

6.2.1. Comparison of vibration-suppressing effects Figure 10 shows the calculated vertical vibration acceleration PSD obtained from an excitation test to simulate actual running by using the aforementioned disturbance.

For the truck frame acceleration (in Fig. 10(a)), the acceleration PSD decreased at around 5 to $12 \mathrm{~Hz}$ by controlling the force of the variable axle dampers from that when the damping force of the axle dampers was not controlled - the conventional passive axle dampers were used (shown by the gray line). The vibration acceleration of the truck frame decreased in the frequency band 5 to $12 \mathrm{~Hz}$ overall using the sky-hook control technique (shown by the green line), while it decreased selectively around the $8 \mathrm{~Hz}$ using the LQG control technique (shown by the orange line).

Figure 10(b) shows the vibration acceleration PSD at the carbody center. When the damping force of the axle dampers was not controlled, a peak is seen at around $8.5 \mathrm{~Hz}$, caused by the first mode bending vibration of the carbody. However, the vibration acceleration decreased in general before and after $8.5 \mathrm{~Hz}$ (or around 5 to $12 \mathrm{~Hz}$ ) using the sky-hook control technique, and selectively around $8.5 \mathrm{~Hz}$ using the LQG control technique. Compared to the case where the damping force of the axle dampers was not controlled, the PSD peak value decreased to $22 \%$ using the sky-hook control technique and to $15 \%$ with the LQG control technique. This means that the LQG control is more effective in reducing the PSD peak value. A similar trend is observed with the carbody vertical vibration acceleration directly above the truck (Fig. 10(c)). These findings demonstrate that it was possible to obtain the intended vibration-reducing effect by setting an appropriate weighting matrix $\boldsymbol{Q}$ when designing the LQG controller.

The above results that show a tendency similar to those of the simulation in $\$ 5$ indicate that vibration is suppressed approximately as intended.

For the PSD value of the truck frame's vertical vibration acceleration around $8.5 \mathrm{~Hz}$, the sky-hook control law and the LQG control law provided approximately the same degree of vibration suppression. Nevertheless, an obvious difference was observed in the vibrationacceleration-peak-value-suppressing effect of the two control laws at around $8.5 \mathrm{~Hz}$ in the carbody center. To investigate the cause of this difference, the authors determined the same phase component $\left(\ddot{z}_{T 1}+\ddot{z}_{T 2}\right) / 2$ of the vertical vibration acceleration in the front and rear trucks and calculated their acceleration PSD values (Fig.11), where $\ddot{z}_{T 1}$ and $\ddot{z}_{T 2}$ denote the vertical 


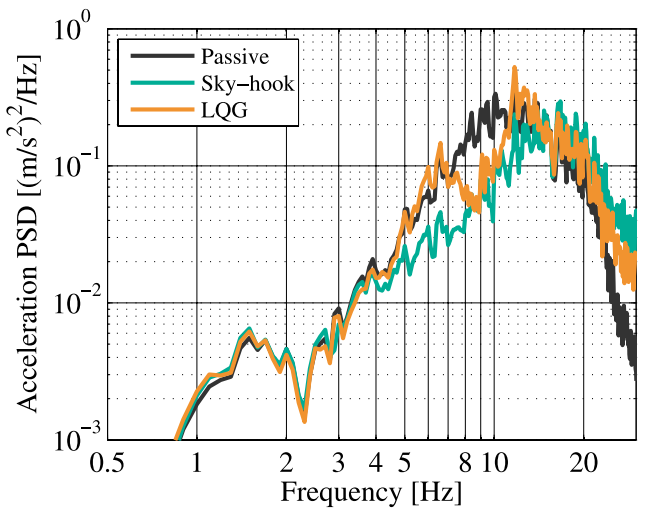

(a) Acceleration PSD of the rear truck frame

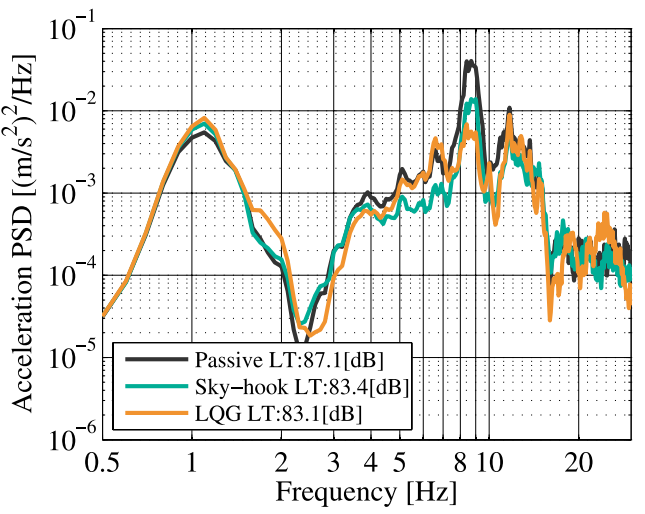

(b) Acceleration PSD at the center of the carbody floor

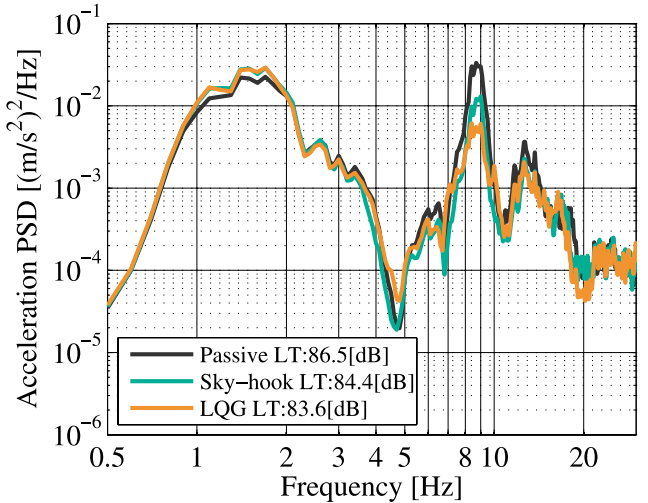

(c) Acceleration PSD at the carbody floor above the rear truck

Fig. 10 Acceleration PSD with/without controlling the force of axle dampers (Experimental results)

translational acceleration of the front and rear trucks respectively, and equation (18) holds.

$$
\ddot{z}_{T i}=\left(\ddot{z}_{W i 1}+\ddot{z}_{W i 2}+\ddot{z}_{T r i 1}+\ddot{z}_{T r i 2}\right) / 2
$$

The PSD value of $\left(\ddot{z}_{T 1}+\ddot{z}_{T 2}\right) / 2$ at the frequency of $8.7 \mathrm{~Hz}$ (equivalent to the natural frequency of the carbody first bending mode) was $0.084\left(\mathrm{~m} / \mathrm{s}^{2}\right)^{2} / \mathrm{Hz}$ when conventional passive axle dampers were used, $0.030\left(\mathrm{~m} / \mathrm{s}^{2}\right)^{2} / \mathrm{Hz}$ under sky-hook control and $0.016\left(\mathrm{~m} / \mathrm{s}^{2}\right)^{2} / \mathrm{Hz}$ under LQG control. This means that the PSD value under LQG control is approximately half that obtained with truck frame sky-hook control. The test results indicate that LQG control law suppresses the first mode bending vibration of the carbody more effectively than sky-hook control law since it selectively reduces the same phase component in the vertical acceleration of the front and rear trucks that greatly influences this vibration. 


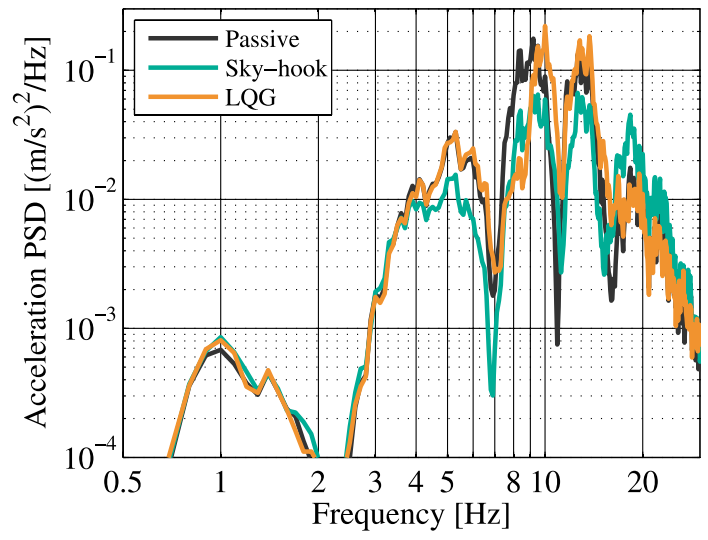

Fig. 11 Same phase component of acceleration $\left(\ddot{z}_{T 1}+\ddot{z}_{T 2}\right)$ PSD of the front and rear trucks (Experimental results)

6.2.2. Comparison of ride comfort improvement effects The legends in Fig.10 show the $L_{T}$ values calculated when vibration was controlled under different conditions. Comparing the $L_{T}$ values in different control laws to those obtained without control, the value at the carbody center was $3.7 \mathrm{~dB}$ lower with sky-hook control and $4.0 \mathrm{~dB}$ lower with LQG control. This indicates that the effect of $L_{T}$ improvement is a little higher with the latter. With this vehicle, vibration in the vicinity of $8.5 \mathrm{~Hz}$ greatly influences the $L_{T}$ value. Therefore, the effect of improving ride comfort is higher with LQG control as it reduces this vibration component more. A similar tendency was also observed just above the truck, in that the $L_{T}$ value decreased by $2.1 \mathrm{~dB}$ under the sky-hook control and by $2.9 \mathrm{~dB}$ under the LQG control.

These results indicate the same tendency as the simulation results in $\S 5$. At the carbody center, however, LQG control provided a slightly lower effect in improving the $L_{T}$ value than that obtained by the simulation. This is presumably because it did not reduce the vibration component not modeled for the carbody center (e.g. the component of the peak acceleration PSD at $7 \mathrm{~Hz}$ ) existing in the frequency band 4 to $8 \mathrm{~Hz}$, which includes important frequencies in evaluating the $L_{T}$ value. On the other hand, the $L_{T}$ value improvement immediately above the truck was higher in the test than in the simulation. This is because the vibration component not modeled in the frequency band 4 to $8 \mathrm{~Hz}$ was smaller, and the component of the first mode bending vibration of the carbody immediately above the truck was larger with the actual car than with the model. The component of the first mode bending vibration of the carbody seems to have become larger, as the dead weight placed in the longitudinal direction under the carbody floor slightly deformed the profile of the carbody first bending mode, which caused a difference between the actual mode profile and that $\phi_{1}(x)$ of the ideal beam model used for the carbody model.

\section{Conclusion}

For the control of the primary suspension of rolling stock, we discussed the effect of reducing, among others, the first mode bending vibration of the carbody by applying a control law based on a vehicle model. For this purpose, we applied the LQG control law, designed and applied a control system based on a model of seven degrees of freedom, and compared the results with those obtained when the truck frame sky-hook control law was applied.

Numerical simulations and excitation tests to simulate running on an actual track at a rolling stock test plant demonstrated that the LQG control law concentratedly reduces the first mode bending vibration of the carbody, more so than with the sky-hook control law that does not consider the rolling stock vibration mode. To compare ride comfort improvement effects, the authors then compared the $L_{T}$ value improvement between cases with and without vibration control. With the test car, the LQG control law provided a ride comfort improvement effect equal to or higher than that obtained under the sky-hook control law.

It is probable that the LQG control law is particularly effective in the following cases: 
Case A : The first mode bending vibration of the carbody is outstanding, with other elastic vibration modes not modeled having a relatively lower effect on ride comfort.

Case B : The natural frequency of the primary suspension is not close to that of the carbody first bending mode.

The truck frame sky-hook control law effectively reduces vibration around the natural frequency of the primary suspension (as with the test vehicle in this study), but does not sufficiently suppress vibration in the frequency band far from the natural frequency. This demonstrates that LQG control law is effective in Case B in particular.

The authors suggest that the appropriate control law should be applied in consideration of the vibration conditions of the object vehicle to improve the vertical ride comfort of actual vehicle. We plan to implement running tests in the future to verify this.

\section{Acknowledgements}

We wish to express our sincere gratitude to those in the Automotive Systems Group at Hitachi, Ltd., who kindly extended their invaluable cooperation in developing the variable axle dampers used in this study.

\section{References}

( 1 ) Suzuki, Y., Akutsu, K., Maebashi, E. and Sasakura, M., Method for Flexural Vibration Damping of Rolling Stock Carbody, Quarterly Report of RTRI, Vol.38, No.3 (1997-9), pp.123-128, ISSN 0033-9008.

( 2 ) Kanbayashi, K., Usui, S., Ohtsuka, T., Matsushima, H. and Dambata, K., Development of an Active Vibration Control Systems for High Speed Railway Vehicles (in Japanese), Proceedings of the 5th Jointed Railway Technology Symposium (J-Rail'98), (1998-11), pp.499-502.

( 3 ) Sugahara, Y., Takigami, T. and Kazato, A., Suppressing Vertical Vibration in Railway Vehicles through Primary Suspension Damping Force Control, Journal of System Design and Dynamics, Vol.1, No.2 (2007-5), pp.224-235.

( 4 ) Kimura, T., Development of Semi-Active Suspension System, Journal of Society of Automotive Engineers of Japan (in Japanese), Vol.58,No.4 (2004-4), pp.76-80.

( 5 ) Nagai, M. and Sawada Y., Active Suspension Control for the Flexible Structure of an Elastic Vehicle Body, Transactions of the Japan Society of Mechanical Engineers, Series C, Vol.53, No.492 (1987-8), pp.1750-1757.

( 6 ) D. Karnopp, M.J. Crospy and R.A. Harwood, Vibration Control Using Semi-Active Force Generators, Transactions of the American Society of Mechanical Engineers, Journal of Engineering for Industry, (1974-5), pp.619-626.

( 7 ) Suzuki, H., Research trends on riding comfort evaluation in Japan, Proceedings of the Institution of Mechanical Engineers Part F: Journal of Rail and Rapid Transit, Vol.212, No.1 (1998-4), pp.61-72.

( 8 ) Yamazaki, K., Kobayashi, I., Sampei, S., Nishimoto, Y. and Kuramata, T., A study on the evaluation of ride comfort (in Japanese), Bulletin of Railway Labor Science Research Institute, Vol.36 (1982-1), pp.57-73, ISSN 0285-8657. 